\title{
A Review on People's Participation for Sustainable Rural Water Supply Systems with Special Reference to Nepal
}

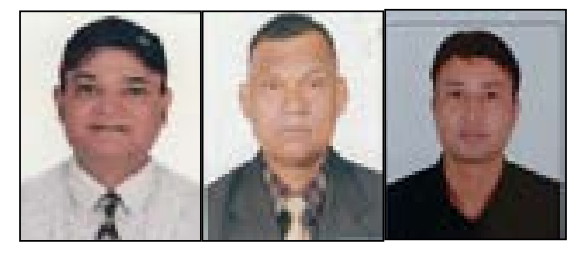

Dr. Khet Raj Dahal, Dr. Narbikram Thapa and Mr. Raju Shiwakoti

Dr. Khet Raj Dahal, Dr. Narbikram Thapa Mr. Raju Shiwakoti

Abstract: This study was carried out during the period from March to August 2018. Published literatures and some unpublished data were collected from different sources and analyzed. It was found that the community people do not have good understanding and adequate participation on the sustainability of water supply systems. They only have interests in the regular flow in taps. They are also less aware in the regular repair and maintenance of water supply systems. Furthermore, the expectation of community is always financial support from local body and donor agency. The governance part of water user's committee was also found unsatisfactory. Thus, the people should be provided with capacity development trainings for the sustainable development of community water supply system. similarly, implementation of water safety plan, and regular monitoring from local body are crucial activities that should be given high emphasis for the sustainability of rural water supply system.

Keywords: Community participation, Sustainable water supply system, Demand Driven Approach, Engineering structures, Nepal

\section{Introduction}

Safe water is one of the most basic human needs. Water is the essential resource for survival and good health. Access to water in the rural community plays a vital role in the overall socio-economic development (Smith et al., 2009).

In developing countries like Nepal, a large portion of the population is often dependent for drinking purposes on raw water that has not been treated in many cases. In one hand, the number of people affected and estimated damages from water-related disasters continue to increase. In other hand, climate change is disrupting the global water cycle and it has increased the frequency and severity of disasters (NPC, 2016).

This study tries to figure out the role of communities in the planning, implementation and sustainability of the water supply systems. This study hopes to acquire the information which would aid in understanding the difficulty in including the citizens to gain sustainable water supply systems in Nepal.

In Nepal, the medical facilities in the rural areas seem to be poor as compared to the urban areas. But disaster risk management aspects have not been considered during survey, design, and implementation stages. This situation does not maintain sustainability of the water supply systems. Thus, the sustainability of water and sanitation systems must be given high priority in a socially accepted manner throughout the country. Still, water supply system in rural community is questionable from disaster risk management point of view. Similarly, livelihood aspect of the people has not been considered. In the rural community, the livelihood of the people depends upon the water available in the vicinity of the community (GON, 2014).
Around $35 \%$ population use tube well and $28.60 \%$ population use hand pump to drink water. Urban population has increased from $13.9 \%$ to $17.07 \%$ respectively during last decade (GoN, 2001;2011). It shows that the migration of rural people is increasing and they are making their shelter in urban area for amenities and opportunities. It is estimated that 20 million to 30 million poor people in the world move each year from rural to urban areas for better opportunities (Smith and Petley, 2009). And they all need piped water supply. There are about 41,205 number of piped water supply systems in operation throughout Nepal. They are all mostly operated by Water User's Committee (WUC) in the rural areas. But it covers only $52.3 \%$ of the population. Many water supply systems are not functioning well. Only $25 \%$ of water supply systems are well functioning. All systems do not have maintenance fund. Only $4.5 \%$ have maintenance funds for the system. There is also a budget allocation gap in water supply systems (SEIU, 2016).

About 82,000 people are killed every year in the world by disasters and all these fatalities are concentrated mostly in developing countries. Most of the urban areas in developing countries are concentrated to disaster because of inadequate management and planning (Dickson, 2012). Ultimately, the direct effect of disaster can be seen on low income generating people. It increases the vulnerability of the community along with the poverty of the country (Lal el al, 2009). In general, there is no consideration of sustainability factor during design and planning phase in the developing countries. They need infrastructures in low investment. Thus, the result of such planning fails to satisfy people in the long run. The sustainability factor must be considered in all aspects of development. In the developing countries, the participatory approach of development in all phases of the project can be the best way of sustainable 
development (Dickson, 2012).

Like other development, pure drinking water is essential for all people. Thus, access to drinking water is necessary for overall socio-economic and environmental existence throughout the world (Beyene, 2012). In Nepal, the Government, NGOs, INGOs and other concerned organization have invested millions of rupees to implement community water supply system. However, even after the completion of the projects, they are still not functioning well. Thus, to make the investment more effective, failure rates of these systems should be reduced throughout the country (NPC, 2016).

According to (Baykedagu, 2006), community water supply schemes can be accomplished by better integration of people who are getting services. People can be involved in planning, design, construction and management of water supply systems in any community project. Failure to mobilize the local people in the project area may cause the low sustainability of the rural water supply system. In Nepal, the lack of ownership, lack of education on water supply, poor management system and low awareness about the use of water are related to low sustainability of the water supply system. There are so many factors, that play a great role for the sustainability of the project, but the major factors are institutional, social, technical, environmental and financial ones. The design period of the water supply system is variable. The rural water supply system is normally designed for 15 -20 years. Most of the water supply systems are not in functional stage after construction of the project throughout the country. This happens due to lack of consideration of sustainability of the project along with lack of adaptation of participatory approach of development (Deneke et al., 2008).

In the context of Nepal, active and meaningful involvement as well as empowerment of stakeholders in different phases such as planning, designing and implementation is called participatory planning. In the planning process, the demand of community must to be taken into consideration. The real needs can be identified if the demand collection is taken from the community (SEIU, 2016).

The completed water supply systems get higher priority for the budget allocation in local body council and in local level planning in Nepal from the past decades due to disruption of the flow in tap. The process begins from the water user's committee (WUC). The WUC submits the demand and request letter in various implementing donor agency and water supply and sanitation division office of a district for the construction and maintenance of water supply schemes. The WUC is more dependent on the donors for the maintenance of the system. This is because of the lack of confidence that they can make water supply sustainable and functional (SEIU, 2016).
The budget of local government is being allocated in the same water supply schemes due to lack of sustainability. The most essential schemes are getting less priority which could fulfill the requirements of communities. In fact, the voice of powerless communities is not properly heard. The marginalized communities are given less priority and their situation is worsening. When resources are not mobilized properly with consideration of demand driven approach, the repetition of budget allocation in these same water supply schemes will remain forever. There are around 270, ooo households, which have gained access to safe drinking water in the country (NPC, 2016). This does not mean that they have access to the best quality of drinking water. However, there are still 700,000 household that use unsafe water in the country. In remote and backward area of the country, thousands of people go for a long walk to get a bucket of water for their use. It is estimated that there is less than 70 percent of the population that has access to safe water throughout the country (GON, 2014, NPC 2016). There is a reality that nobody can ascertain quality of water, which people are using as pure drinking water.

Even people who have access to piped water are not sure if it is safe drinking water. Like others, the water supply system also affects the sanitation, hygiene and ultimately invites disasters in the community. The campaign of open defecation free program cannot be achieved until and unless we manage adequate safe drinking water in each household of the community. Most of the epidemics and disasters are caused due to the unsafe water and sanitation system in the community. Thus, to minimize water, sanitation and hygiene (WASH) related disasters, it is necessary to achieve sustainable water supply system in the community (GoN, 2014).

\section{World's History of water supply system}

The history of ancient water supply systems started from the Roman civilizations. In the historical times, Greeks and later Romans achieved a high level of water supply technologies that has greatly influenced modern achievements in water engineering and management throughout the world. During the Neolithic age (ca. 5700-280o BC), the first successful efforts to control the flow of water were used for the irrigation, which was needed for agriculture development. The revolution of agriculture started in the past (about 6000 to 7000 years ago) in Mesopotamia and Egypt. These prehistoric irrigation canals still exist as the historic symbols of development. However, many urban hydraulic systems became out-of-date at a later stage especially, in the Bronze Age (Jansen, 1989).

If we explore the history of development, there are several amazing examples of urban water supply systems from about the mid-third millennium BC. MohenjoDaro, a major urban center of the Indus Civilization, 
developed a sophisticated system for water supply and sewerage in the past. Water was collected from more than 700 wells and supplied to domestic as well as public demands for bath (Adams, 1981; Jansen, 1989).

Another example is the city of Eshnunna $(80 \mathrm{~km}$ northeast of the present Baghdad), where archaeological excavations exposed sewers constructed of brick, with laterals connecting to houses (Gray, 1940). In the Sumerian city of Nippur, the excavations exposed clay pipes as well as tee- and angle-joints. Rainwater harvesting and collection in cisterns for urban water supply was practiced at about the same period in Jawa in north eastern Jordan. Another collection system, was developed in Persia, again in the same period for ground water collection (Hassan, 2003). Somewhere, it was called as "QANATA".

"QANATA" - a subterranean system of tunnels connecting wells and dug wells - was designed to collect and transport water. This method was very popular and sometimes was used over long distances, from highlands to lowlands. In Iran, over millennia, 22,00o quanta units were constructed, comprising more than 270 thousand kilometers of underground channels for carrying water. Furthermore, in the 1960 s, $75 \%$ of all the water used in that country for irrigation and domestic consumption was by such systems (Wulff, 1968). Over the centuries, the technology was transferred to all civilizations and become known with different names in different countries, such as 'Karez' (Afghanistan and Pakistan), 'Kanerjing' (China), 'Falaj' (United Arab Emirates) and 'Foggara/Fughara' (North Africa).

This technology could not expand throught the world. Later advanced technology developed and 'QANATA' was disappeared. In Nepal, this type of technology could not observed (Nepal IRC, 1988).

In the past centuries, starting from the Bronze Age, hydraulic technologies were also developed in Greece during several stages of the Greek civilization. Other new and more advanced water technologies were also invented during this period. The Romans, who's Empire replaced the Greek rule in most part of this area, developed the technologies further, changing their application scale from small to large and implemented them in every large city. The Greek and Romanian water technologies are popular cultural heritages as well as the underpinning of modern achievements in water engineering field. The written documents enabled those technologies to pass to modern societies in the world (Wulff, 1968).

\section{Rural Water Supply and Sanitation Development Activities in Rural Nepal}

The history of modern organizational/governmental efforts to develop drinking water supply sector is not very long in Nepal. In the past, the Ministry of Water
Resources was originally responsible for all the drinking water supply under its Department of Irrigation and Water Supply, which was established in 1966 (Nepal IRC, 1988). The department performed its roles till 1971 and then, the department separated into two parts; Department of Irrigation and Department of Water Supply and Sewerage (DWSS). During past decades especially in Panchayat Regime, the Ministry of Panchayat and Local Development (MPLD) focused the responsibility for small-scale village level water supply schemes and implemented number of construction projects as part of its local development program. Criteria for such schemes developed by MPLD were: (i) a system should serve maximum of 1500 people, (ii) the pipeline should not be longer than 5 kilometers and (iii) the cost should not be more than NRs. 50,000.00. Settlements and schemes that did not meet the above criteria were managed by DWSS through consultants and / or contractor's involvement for construction of the schemes under the Ministry of Water Resources (Nepal IRC, 1988). The system as stated here and the designed structure lasted for 15 years.

Till 1970, the national drinking water supply coverage was only $3.7 \%$ of the total population of Nepal. This status was extremely low in the rural area of Nepal. Generally, many planners did not emphasize on improving the water supply and sanitation condition of the country especially in the rural areas of Nepal (IRS 1997). They emphasized to improve the situation in the urban areas of Nepal. Later, in the international arena, two women, one British economist-Barbara Ward, and the other American anthropologist-Margaret Mead individually initiated the activity for drinking water supply at the United Nations (UN) Conference on Human Settlement (HABITAT) in Vancouver in 1976. They emphasized on formulation of favorable policy and approvals on water supply and sanitation for all developing countries of the world (IRC, 1997; UN 2018).

Then the General Assembly of UN subsequently passed the resolution on the International Drinking Water Supply and Sanitation Decade: 1980-1990. To express the commitment on the International Drinking Water and Sanitation Decade, HMG Nepal also announced the national priority to have accessible piped drinking water supply by the end of 6th five -year plans in the country. The program was launched accordingly. In 7 th plan, it is mentioned that only $17.9 \%$ and $79.9 \%$ of rural and urban people respectively, have got access to drinking water. But it did not mention the actual coverage in the achievement of the 6th Five Year Plan. The column of achievement is blank (Seventh Plan, 2042-2047 B.S). Likewise, it was mentioned in the Eight Plan, the target was set to 72 percent of population coverage for safe drinking water supply throughout the country (NPC, 2016). 
Organizations/Institutions Involved in Drinking Water and Sanitation Development Activity

In addition to the Government of Nepal, Red Cross Society, Danish International Development Agency (DANIDA), Finnish International Development Agency (FINNID), United Nations International Children's Funds (UNICEF), Redd Barna, World Bank, United Mission to Nepal (UMN), HELVATES, European Commission (EC), Water Aid, Save the Children Fund United Kingdom (SCF-UK), Lutheran World Service (LWS), Save the Children Fund United States of America (SCF-USA), Asian Development Bank, (RWSS- FUND) FUND Board and number of other Community Based Organizations (CBOs) have been involved in providing and improving water and sanitation services and facilities in the rural areas of Nepal since past decades (NPC, 2016). The aforesaid organizations/institutions are only some principal organizations and institutions working in this sector.

\section{Community Participation in the context of Nepal}

The Government, donors, policymakers, NGOs, INGOs, emphasized the value and potential benefits of participatory approaches. The participation of community is given more emphasis because the key concern was the failures in state-led projects for development. For the economic development and service delivery, the focus on "community participation" is given more emphasis for the internal coherence and solidarity in communities. It provides the inspiration among beneficiaries, ensures accountability, and transparency efficiency (Heck, 2003).

Community Participation for the development in various sectors has been increasing in developing countries like Nepal since 1980 `s. This is now an accepted component of the project's design. It has flourished the concept of people's empowerment, local knowledge and community ownership, which are the most important ingredients of project success and sustainability (Bastian et al., 1992).

In Nepal, the project can be effective and efficient when real beneficiaries of any proposed project are themselves directly involved in the shaping of their future environment. Participatory approach of development is therefore, the appropriate process of development. In this process, people are not only the beneficiaries of change in the development process but more importantly they act as the agents of the change. Participation as a concept of development means getting the public involved in taking decisions that affect their well-being in their area or community. The purpose of participatory approach is not to make the process simpler or "efficient" but to make sure that local conditions and needs are taken into consideration during development. (ADB, 2012).
Participation is an approach through which beneficiaries and other stakeholders can influence project planning, decision-making, implementation and monitoring phases of the development. On the other hand, participation is a condition for project ownership, successful implementation and sustainability of the projects especially in the developing countries. Participation does not mean acceptance of all ideas from diverse groups of the community. It also considers the local and indigenous knowledge during development. However, care must be taken so that intellectual knowledge is not influenced by that of the indigenous community (Kasiaka, 2004).

David (2014) has observed that the community participation is essential in ensuring sustainability of rural development projects in developing countries. It has its own shortcomings. It is said that participatory planning is time consuming and a complex process. The process takes some months to be understood. As a result, beneficiaries expecting to get quick results may be discouraged. Thus, sometimes, participatory planning is a threat to experts where they are serving. The reason behind this is that some development experts tend to feel they know better than the community people.

Besides this, lack of capacity at the community level is one of the challenges in sustenance of water and sanitation facilities in Nepal. Communities are often unable to repair and maintain the water sources without having to seek external support from donor and district. This is particularly due to lack of technical capacity at the community level to handle technical breakdown of the water sources and lack of knowledge on the impacts of land use on water quality of the system (GON, 2014).

Participatory planning in Nepal was authentically described in 1999, when the Local Self Governance Act, 1999 and Local Self Governance Rule, 2000 was introduced. A total of 14 steps of planning process were introduced in this Act and Regulation.

\section{Sustainable Development}

Sustainable Development means development that meets the needs of the present, without compromising the ability of future generations to meet their own needs (UNICEF, 2013). It has been defined in many ways, but the most frequently quoted definition is from Our Common Future, also known as the Brundtland Report:

The report explains "Sustainable development is the development that meets the needs of the present without compromising the ability of future generation to meet their own needs". It contains two key concepts as presented below.

- "The concept of needs, the essential needs of the world's poor, to which overriding priority 
should be given", and

- "The idea of limitation imposed by the state of technology and social organization on the environment's ability to meet present and future needs".

\section{Approaches to Water and Sanitation System in Nepal}

Different countries used different approaches to provide water facilities in the world. The main approaches to water and sanitation delivery are the supply and demand driven approach. It is observed that both approaches (demand driven and supply-driven approach) are limited to access to need.

It was revealed that under the supply-driven approach people possibly mismanaged state authorities with limited resources, while under demand-driven approach a section of the population living in the community might be unable to effectively demand for water infrastructures in their life (Mugumya, 2013).

\section{Supply-Driven Approach to Water and Sanitation Provision in Nepal}

Nepal is heavily supply driven with the centralized government system in delivery and management of infrastructure. Under the supply-driven concept, the decision depends on the central government (GON, 2014). Water and sanitation facilities provided in Nepal, were therefore regarded as facilities for the centralized government. There were no properly constituted structures to promote community ownership, operation and maintenance. Therefore, nobody cared about how the facilities were run leading to situations, where most projects became useless in the communities. The unsustainable nature of projects provided under this supply-driven concept informed the decision makers that led to the introduction of the demand-driven concept in 2008 when the Local Governance and Community Development Program (LGCDP) was introduced.

\section{Demand Driven Approach to Water and Sanitation System in Nepal}

The demand-driven approach in rural safe water supply emphasizes three interrelated values, i.e., individual decision-making, personal responsibility, and citizen participation respectively. The demand-driven reform efforts with implications on rural safe water supply, accessibility and sustainability include a move toward market-oriented provision, decentralization (reliance on local governments) and communities for service delivery (community participation), user fees and cost recovery along with private sector involvement (Penker et al., 2012). All these have varying implications for safe water management, equity and sustained access to safe water to the community people (Regmi et al., 1999).

\section{The Community in the context of Nepal}

In general, a community may be defined as a set of meaningful social connections in a group of any size, where members have something in common. It is social and it is a web of relationships. A community operates within certain boundaries that are agreed among members either tacitly or explicitly everywhere in the world. Each community establishes traditions and patterns of behavior, which may be implied or written as rules in common. Members of community share a bond such as location, interests, background or identity, situations or experiences (Anheier \& Toepler, 2010). An alternative definition of community is more functional and focused on the purpose of the activity. For instance, Porter and Kramer, (2006) defines a virtual community as an "Aggregation of individuals or business partners, who interact around a shared interest, where the interaction is at least partially supported and/or mediated by technology and guided by some protocols or norms".

\section{Non-Governmental Organizations in Nepal}

In general, NGOs are components of social movements. Similarly, civil society is the broader concept to cover all social activities by individuals and groups. Usually, "Society is being composed of three sectors: government, the private sector and civil society, excluding businesses" (Willetts, 2018). It is difficult to figure out the exact contribution of NGOs in Nepal. But in terms of financing sector in water and sanitation, there is a lot of field evidence for the significant presence of local NGOs and Community Based Organizations (CBO). In Nepal, Non-Governmental Organization is indeed helping to accelerate WASH sector effectively.

\section{Processes of Rural Water and Sanitation system in Nepal}

"The planning for management and development of water resources should be pursued at the lowest possible level of Government and with involvement of all key stakeholders". In general, the planning process represents the application of scientific method in the analysis of human behavior and societal problems. In the context of social, economic, political structures, the planning process cannot go ahead without the objective of interaction between community and political leaders" (Cosgrove et al., 2015).

"The planning process is operationalized based on the problem-solving model". Different people have suggested different forms of the process. However, they all have the same characteristics. According to Conyers et al., (1984), the characteristics of a real planning process includes: "It is problem solving, dealing with the identification and solution of societal problems, it is multi-objective, seeking to address itself to many objectives at the same time when a problem is being solved, it is cyclical, implying a continuous process 
as it attempts to adjust itself to the changing norms, behavior and attributes of society; it is evolutionary, developing by natural processes from rudimentary to more highly organized state in terms of methods and tools of analysis; in another perspective, the planning process evolves from the aspirations of society and must therefore be society-based; and it is interdisciplinary, involving the integration of chartered planners, sectoral specialists institutionalized societies those concerned with decision-making and other beneficiaries".

\section{Community Participation and Project Sustainability}

Many resources for social welfare services are shrinking everywhere. Population pressures, changing priorities, economic competition, and demands for greater effectiveness are all affecting the course of social welfare in the world (Charles, 1994). The utilization of non-professionals through citizen involvement mechanisms to address social problems has become more common place in the world (Kaufman et al., 1996).

Kaufman and Poulin (1996) explained that "Authentic community participation increases the sustainability of the community development projects and this can only be achieved through a people centered development. Effective community participation may lead to social and personal empowerment, economic development, and socio-political transformation".

The issue of sustainability relating to development activities began since past decades. However, it became important to government, donors and development theorists from the 1980s (Scoones, 2007). Furthermore, it concerns with the issue of project sustainability and also comes from the mounting pressures from domestic constituencies (Brown, 1998). These pressures have made governments, donor organizations and development workers start to think about the effectiveness and the value of aid being delivered to Third World Countries over the past decades. "Donor organizations and development workers are concerned that aid being delivered seems to give few positive impacts to the recipient countries". Most of the projects seem to end, when the donor agencies withdraw the investment. The USAID and World Bank's post evaluation shows that most development interventions have low levels of sustainability after the completion of the project in Nepal and some other countries in the world similar to Nepal (Goldsmith et al., 1992).

For sustainability study of community water supply system, the definition of seems more appropriate. This definition considers all aspects required for a sustainable water supply system and makes the requirements more operational. A water and sanitation service is sustainable when: it is functioning and being used; it can deliver an appropriate level of benefits (quality, quantity, convenience, continuity, health) to all; it continues to function over a prolonged period; its management is institutionalized; its operation, maintenance, administrative and replacement costs are recovered at the local level; it can be operated and maintained at local level with limited but feasible external support, and it does not affect the environment negatively (Heck, 2003).

\section{Water and Sanitation Problem at Global Level}

In the world, about 2.6 billion people have access to improved drinking water sources (MDG, 2009). But 663 million have still not gained the access to safe drinking water sources. At least 1.8 billion people globally use drinking water sources which have fecal contamination. The use of improved drinking water source has increased from $76 \%$ to $91 \%$ between the years of 1990 to 2015 in Nepal. However, the water scarcity is more than $40 \%$ globally, and it is projected to rise and 1.7 billion people are currently living in river basin. But the use exceeds the recharge of the ground water table. More than $80 \%$ waste water is discharged into rivers or sea. In general, each day nearly 1000 children die due to water and sanitation related diseases in the world (UN 2018). The problem of water scarcity, poor water quality and inadequate sanitation system negatively impact food security of the people across the world. But due to poverty or low quality of infrastructure, every year millions of people die from diseases associated with inadequate water supply, sanitation and hygiene. By 2050, at least one in four people is likely to live in a country affected by chronic or recurring shortages of fresh water in the world (UNICEF, 2013; UN 2018).

\section{Water and Sanitation Problem at Regional Level}

In the past decades, there have been worthy gains in WASH services in South Asia especially in SAARC countries. They have given high priority in WASH and become the political agenda for development. In 2015, it is estimated that more than half of the SAARC region's citizen (approximately 1.1 billion people) lived without access to either water or sanitation. Moreover, more than $40 \%$ of people without access to toilet and $25 \%$ without access to clean drinking water live in the South Asian Region including Nepal. In the countries of this region, people who are living with least WASH access are those who are below the poverty line (World Bank, 2016). The people who have less access to WASH are those who are socially, economically, geographically and technically hard to reach (Baykedagn, 2006).

All South Asian countries have already signed up to relevant human rights conventions on water and sanitation. Bangladesh and Nepal have incorporated the agenda into their constitutions too. Government of India has launched the Clean India campaign, a huge program aiming to eliminate open defecation effectively. In Pakistan also, the Government has launched a national program on hygiene behavior change campaign in collaboration with UNICEF and Water Aid. Policies 
and strategies abound and resources are committed in these countries since past years effectively (Water AID, 2016). Evidences show that South Asia has the largest number of people under served by WASH services as compared to the developed countries. People, especially women and girls, disables, minorities, old people, and people of certain castes (untouchables and low castes) and transgender people face the greatest challenges in accessing their rights to water and sanitation facilities in these countries though the government is actively working to eliminate the discrimination in the society (UNICEF, 2013; Water AID, 2016).

It is estimated that about 705 million people still practice open defecation in rural areas in South Asian countries. However, about 74 million people, who live in urban areas of the same countries, use safe toilets for defecation (WHO, 2012). Therefore, improvement of sanitation coverage with access to safe drinking water is of great importance to achieve the Sustainable Development Goals (SDG).

\section{Water supply coverage in Nepal}

Since 2000, water supply and sanitation programs have got high priority in Nepal. International water supply and sanitation decade (1981-90) encouraged to do it. Sanitation was one of the components of water supply projects till 2010. Afterwards it became a program of the national movement guided by Sanitation and Hygiene Master Plan 2011 (SEIU, 2016).

According to the government report, nineteen (19) districts have coverage of water supply and sanitation of more than 90\%, 41 districts 90\% and 14 districts below $80 \%$. This sector needs calculating actual coverage in view of functionality, durability, and quality of supplied water in all projects. This is necessary for measuring SDG target related to water supply and sanitation (NMIP, 2014; SEIU, 2016).

Water and sanitation are necessities for all human beings. Thus, the government of Nepal had developed plans and policies to increase water and sanitation coverage throughout the country. The country has prepared the National WASH sectoral Development Plan 2016 for the coming 15-years. All technical, social and operational issues have been analyzed in this plan. It has also addressed the key strategic issues for our future interventions and subsequent investment in the sector effectively and efficiently (NMIP, 2014).

Water supply and sanitation are the emerging issues in all the organizations along with stakeholders or partners of this sector. The program needs active participation from the community level. However, due to the low participation of the community in the planning and implementation phases, many programs are not running effectively. This is due to lack of proper management. As a result, many community water supply projects are not functioning (WHO, 2012; SEIU, 2016).

\section{Conclusions}

The study showed that the people are not aware and the government is not so supportive to handle the systems that could be sustainable in many cases throughout the developing countries of the world. The full community participation seems to be a long process that leads to delays in the implementation of water and sanitation system at the community level.

There is a need of capacity development for community to sustain the water supply schemes. However, there is some problem in meaningful participation of the community members in project cycle management due to busy agricultural farming season, lengthy discussions in the meeting and severe poverty.

Similarly, implementation of water safety plan and regular monitoring from local body are crucial activities that should be given high emphasis for the sustainability of rural water supply system. The governance part of water user's committee was found unsatisfactory. Thus, the people should be provided with capacity development trainings for the sustainable development of community water supply system.

Dr. Khet Raj Dahal is the campus chief of Lumbini International Academy of Science and Technology (LIAST), Lalitpur, Nepal. He completed his PhD from the department of Environmental Science and Engineering, Kathmandu University in 2014. He has been working in different field of engineering including professional teaching for 25 years.

Corresponding address: dahal.khetraj@gmail.com

Dr. Narbikram Thapa, PhD, has been working in various national and international organizations for 35 years especially in humanitarian and development works. Currently he has been working as an Academic Director in Lumbini International Academy of Science and Technology (LIAST), Manbhawan, Jawalakhel, Lalitpur, Nepal.

\section{E-mail: nbthapa2012@gmail.com}

Mr. Raju Shiwakoti, is the M.Sc. Student of Lumbini International Academy of Science and Technology (LIAST), Jawalakhel, Lalitpur. Nepal. He completed his B.E (Civil) in 2007 from Kantipur Engineering College (KEC), Dhapakhel, Lalitpur. He is working as a shelter officer in Oxfam, Nepal.

\section{E-mail: shiwaraju@gmail.com}




\section{References}

Adams R. (1981). Heartland of Cities: Surveys of Ancient Settlements and Land Use on the Central Floodplain of the Euphrates. University of Chicago Press, Chicago, USA.

Baykedagn, G. 2006, An Assessment of Challenges of Sustainable Rural Water Supply: The Case of Ofla Woreda in Tigray Region.

Beyene, H.A. 2012. Factors affecting the rural water supply systems: the case study of Mecha Woreda, Amhara region Ethiopia, Master thesis, Cornell University, Ethiopia.

Bastian, S. and N. Bastian(1992)Assessing participation, Konark Publishers PVT Ltd.

Brown, D. R. 1998, Evaluating institutional sustainability in development programmes: beyond dollars and cents, Journal of international development, Elsevier.

Conyers, D. \& Hills, P. (1984). An Introductory to Development Planning in Third World. New York.

Cosgrove, W. J., and D. P. Loucks (2015), Water management: Current and future challenges and research directions, School of Civil and Environmental Engineering, Cornell University, Ithaca, New York, USA.

Charles K. Bens.1994. Effective citizen involvement: How to make it happen, Wiley.

Dickson, E. Baker, J. L. Hoornweg, D and Tiwari, 2012, Urban Risk Assessments(URA): Understanding Disaster and Climate Risk in Cities, Washington D.C. The World Bank.

Deneke, I , Habtamu, A. H. (March 2008), Researchinspired Policy and Practice Learning in Ethiopia and the Nile region, The Sustainability of Water Supply Schemes A case study in Alaba Special woreda, Addis Ababa, Ethiopia.

Goldsmith \& Brinkerhoff, 1992, Promoting the Sustainability of Development Institutions: A Framework for Strategy, Journal of international development, Elsevier.

Gray, H. F. (1940). Sewerage in Ancient and Medieval Times, Sewage Works Journal, 939 - 946.

Gray, H. F. (1940). Sewerage in Ancient and Medieval Times, Sewage Works Journal, 12 (5), 939 - 946.

H. Anheier \& S. Toepler (eds), 2010, International Encyclopedia of Civil Society,University of Quinsland, Australia.

Hassan, F. A. (2003). Water management and early civilizations: From cooperation to conflict. In F.A. Hassan, M. Reuss, J. Trottier, C. Bernhardt, A. T. Wolf, J. Mohamed-Katerere, and P. van der Zaag (Eds.), History and future of shared water resources (PCCP Series No. 6). Paris: UNESCO.
Heck, B.V(2003), Guidelines on Beneficiary Participation in Agricultural and Rural Development, Rural Institutions and Participation Service, Rural Development Division, Rome Italy.

IRC International Water and Sanitation Centre. (1997), Community Participation in Water Supply Projects. Qandahar- Afghanistan: United Nations Office for Project services.

Jansen, M. (1989). Water Supply and Sewage Disposal at Mohenjo-Daro, World Archaeology, The Archaeology of Public Health), pp. 177-192 .

Kasiaka, K. (2004), Participatory Planning and Sustainability of Water TASAF.

Kaufman and Poulin, 1996, Community Involvement in Cultural Activities: Theories and Concepts, Malaysia, International Islamic University.

Lal, P.N, Singh R and Holland, (2009), Relationship between Natural Disaster and Poverty : A Fiji Case Study, United Nations International Strategy for Disaster Reduction Secretariat's 2009 Global Assessment Report on Disaster Reduction, International Strategy for Disaster Reduction (ISDR).

NPC, 2016. The Millennium Development Goals Final Status Report, Government of Nepal National Planning Commission Singha Durbar, Kathmandu.

Nepal IRC International Water and Sanitation Centre, The Hague, The Netherlands 1988, Community Water Supply and Sanitation Programm Pokhara, Western Development Region,Nepal.

Penker, M.\& Hogl, K, (2012). From supply to demand driven water governance: challenging pathways to Safe Water Access in Rural Uganda Resty Naiga, Paper to be presented at the Conference "Institutions for Collective Action.

Regmi RC, Fawcett B. (1999), integrating gender needs into drinking-water projects in Nepal. Gender and Development, Nepal.

Smith, K. and Petley, D. N (2009). Environmental Hazards: Assessing Risk and Reducing Disasters, $5^{\text {th }}$ Edition, Australia, Institute of Australian Geographers.

Scoones, Ian, (2007), Sustainability, Development in Practice, University of Sussex, Brighton,Germany.

UN, 2018, Sustainable Development Goal, Goal 6: Ensure access to water and sanitation for all, World Water Development Report, facts and figures, Washington DC,USA.

WHO, UNICEF, 2012, Joint Monitoring Report.

Water AID,2016-2030, South Asia Regional Strategy.

Wulff, H. E. (1968), The Qanats of Iran, Scientific American, April 1968. 